\title{
THE MARKET PRICE OF CREDIT RISK: AN EMPIRICAL ANALYSIS OF INTEREST RATE SWAP SPREADS
}

\author{
Jun Liu \\ Francis A. Longstaff \\ Ravit E. Mandell \\ Working Paper 8990 \\ http://www.nber.org/papers/w8990 \\ NATIONAL BUREAU OF ECONOMIC RESEARCH \\ 1050 Massachusetts Avenue \\ Cambridge, MA 02138 \\ June 2002
}

\begin{abstract}
We are grateful for the many helpful comments and contributions of Don Chin, Qiang Dai, Robert Goldstein, Gary Gorton, Peter Hirsch, Antti Ilmanen, Deborah Lucas, Josh Mandell, Yoshihiro Mikami, Jun Pan, Monica Piazzesi, Walter Robinson, Pedro Santa-Clara, Janet Showers, Ken Singleton, Suresh Sundaresan, Abraham Thomas, Rossen Valkanov, Toshiki Yotsuzuka, and seminar participants at Barclays Global Investors, Citigroup, Greenwich Capital Markets, Invesco, Mizuho Financial Group, Simplex Asset Management, UCLA, the 2001 Western Finance Association meetings, the 2002 American Finance Association meetings, and the Risk Conferences on Credit Risk in London and New York. We are particularly grateful for the comments and suggestions of the editor William Schwert and an anonymous referee. All errors are our responsibility. The views expressed herein are those of the authors and not necessarily those of the National Bureau of Economic Research.
\end{abstract}

(C) 2002 by Jun Liu, Francis A. Longstaff and Ravit E. Mandell. All rights reserved. Short sections of text, not to exceed two paragraphs, may be quoted without explicit permission provided that full credit, including (C) notice, is given to the source. 
The Market Price of Credit Risk: An Empirical Analysis of Interest Rate Swap Spreads

Jun Liu, Francis A. Longstaff and Ravit E. Mandell

NBER Working Paper No. 8990

June 2002

JEL No. E4

\begin{abstract}
This paper studies the market price of credit risk incorporated into one of the most important credit spreads in the financial markets: interest rate swap spreads. Our approach consists of jointly modeling the swap and Treasury term structures using a general five-factor affine credit framework and estimating the parameters by maximum likelihood. We solve for the implied special financing rate for Treasury bonds and find that the liquidity component of on-the-run bond prices can be significant. We also find that credit premia in swap spreads are positive on average. These premia, however, vary significantly over time and were actually negative for much of the 1990s.
\end{abstract}

\author{
Jun Liu \\ UCLA \\ Francis A. Longstaff \\ Ravit E. Mandell \\ Anderson School \\ UCLA \\ Salomon Smith Barney \\ Anderson School \\ 110 Westwood Plaza, Box 951481 \\ Los Angeles, CA 90095-1481 \\ and NBER \\ francis.longstaff@anderson.ucla.edu
}




\section{INTRODUCTION}

One of the most fundamental issues in finance is how the market compensates investors for bearing credit risk. Events such the flight to quality that led to the hedge fund crisis of 1998 demonstrate that changes in the willingness to bear credit risk can have dramatic effects on the financial markets. Furthermore, these events indicate that variation in credit spreads may reflect both changes in perceived default risk and in the relative liquidity of bonds. Understanding the risk and return tradeoffs for these types of securities may become even more important in the future if the supply of U.S. Treasury securities available in the market decreases.

This paper studies the market price of credit risk incorporated into what is rapidly becoming one of the most important credit spreads in the financial markets: interest rate swap spreads. Since swap spreads represent the difference between swap rates and Treasury bond yields, they reflect the difference in the default risk of the financial sector quoting Libor rates and the U.S. Treasury. In addition, swap spreads may include a significant liquidity component if the relevant Treasury bond trades special in the repo market. Thus, swap spreads represent an important data set for examining how both default and liquidity risks influence security returns. The importance of swap spreads derives from the dramatic recent growth in the notional amount of interest rate swaps outstanding relative to the size of the Treasury bond market. For example, the total amount of Treasury debt outstanding at the end of June 2001 was $\$ 5.7$ trillion. In contrast, the Bank for International Settlements (BIS) estimates that the total notional amount of interest rate swaps outstanding at the end of June 2001 was $\$ 57.2$ trillion, representing ten times the amount of Treasury debt.

Since swap spreads are fundamentally credit spreads, our approach consists of jointly modeling the interest rate swap and Treasury term structures using the reducedform credit framework of Duffie and Singleton (1997, 1999). To capture the rich dynamics of the swap and Treasury curves, we use a five-factor affine term structure model which allows the swap spread to be correlated with the riskless rate. In addition, our specification allows market prices of risk to vary over time to reflect the possibility that the willingness of investors to bear credit and liquidity risk may change. We estimate the parameters of the model by maximum likelihood. The data for the study spans nearly the full history of the swap market. We show that both the swap and Treasury term structures are well described by the five-factor affine model.

A number of interesting results emerge from this analysis. First, we solve for the short-term riskless rate implied by Treasury bond prices. We find that the implied riskless rate can differ substantially from the Treasury-bill rate and is often much

higher. This is consistent with the widespread view on Wall Street that because of 
the extreme liquidity of Treasury bills, their yields tend to underestimate the effective riskless rate. Since the implied short-term riskless rate could also be interpreted as special repo rate for the on-the-run Treasury bonds in the sample, we contrast them with repo rates for generic or general Treasury collateral. ${ }^{1}$ We find that these implied special repo rates are slightly less than the general repo rates on average, suggesting that the prices of the on-the-run Treasury bonds in the sample include premia for their liquidity or specialness relative to off-the-run Treasury securities. These specialness premia can be large in economic terms. For example, the specialness premium for the ten-year Treasury note can be as much as 0.57 percent of its notional amount. The estimated specialness premia match closely those implied by a sample of market term special repo rates provided to us.

We then solve for the implied spread process. We find that this spread varies significantly over time, but is nearly zero for an extended period during the mid to latter 1990s. Interestingly, much of the variation in the implied credit spread is related to the difference between the general and implied special repo rates, suggesting that changes in the liquidity of Treasury bonds may be one of the major driving factors of swap spreads.

Finally, we examine the implications of the model for the market prices of interestrate and credit-related risk. Consistent with previous research, we find that there are significant time-varying term premia embedded in Treasury bond prices. We also find that there are significant credit premia embedded in the swap curve. On average, these premia are positive, ranging from 0.1 basis points for a one-year horizon to 45 basis points for a ten-year horizon. These credit premia also display substantial time variation. Surprisingly, we find evidence that credit premia were often negative during an extended period in the 1990s. These results suggest that there have been major changes over time in the expected returns from bearing the default and liquidity risk inherent in interest rate swaps.

This paper complements and extends the recent paper by Duffie and Singleton (1997) who apply a reduced-form credit modeling approach to the swap curve and examine the properties of swap spreads. Our results support their finding that both default-risk and liquidity components are present in swap spreads. By modeling both the swap and Treasury curves simultaneously, however, we are also able to address the issue of how credit risk is priced in the market, which is the primary focus of this paper. Another related paper is He (2000) who independently uses a multi-factor affine term structure framework similar to ours in modeling swap spreads. While He does not estimate the parameters of his model, our empirical results provide support for both swap spread modeling frameworks. Grinblatt (2001) models the swap spread

\footnotetext{
${ }^{1}$ In a recent paper, Duffie (1996) studies the causes and effects of special repo rates in the Treasury repo market. See also Sundaresan (1994), Jordan and Jordan (1997), Buraschi and Menini (2001), and Krishnamurthy (2001).
} 
as the annuitized value of an instantaneous convenience yield. If this convenience yield is interpreted as the liquidity component of the spread process, then our results can also be viewed as providing support for the implications of his model. Other related papers include Sun, Sundaresan, and Wang (1993) who study the extent to which counterparty credit risk affects market swap rates, and Collin-Dufresne and Solnik (2001) who focus on the spread between Libor corporate rates and swap rates.

The remainder of this paper is organized as follows. Section 2 explains the framework used to model the swap and Treasury term structures. Section 3 describes the data. Section 4 discusses the maximum likelihood estimation of the model. Section 5 focuses on the implications of the results for the liquidity of Treasury securities. Section 6 discusses the empirical results about the properties of swap spreads. Section 7 presents the results about the pricing of default and liquidity risk. Section 8 summarizes the results and makes concluding remarks.

\section{MODELING SWAP SPREADS}

To understand how the market prices credit risk over time, we need a framework for estimating expected returns implied by the swap and Treasury term structures. In this section, we use the Duffie and Singleton (1997, 1999) credit modeling approach as the underlying framework in which to analyze the behavior of swap spreads. In particular, we jointly model the swap and Treasury term structures using a five-factor affine framework and estimate the parameters of the model by maximum likelihood. ${ }^{2}$

Recall that under standard no-arbitrage assumptions, the value $D(t, T)$ of a riskless zero-coupon bond with maturity date $T$ can be expressed as

$$
D(t, T)=E_{Q}\left[\exp \left(-\int_{t}^{T} r_{s} d s\right)\right]
$$

where $r$ denotes the instantaneous riskless rate and the expectation is taken with respect to the risk-neutral measure $Q$ rather than the objective measure $P$. In the Duffie and Singleton $(1997,1999)$ framework, default is modeled as the realization of a Poisson process with an intensity which may be time varying. Under some assumptions about the nature of recovery in the event of default, they demonstrate that the value of a risky zero-coupon bond $C(t, T)$ can be expressed in the following form

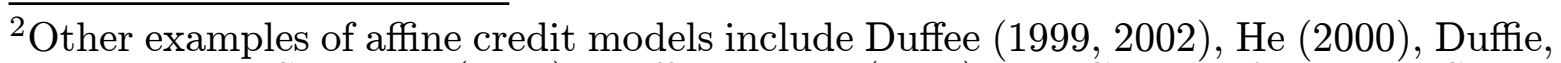
Pedersen, and Singleton (2000), Duffie and Liu (2001), and Colin-Dufresne and Solnik (2001). 


$$
C(t, T)=E_{Q}\left[\exp \left(-\int_{t}^{T} r_{s}+\lambda_{s} d s\right)\right]
$$

where $\lambda$ is a credit-spread process. ${ }^{3}$ They also show that this credit-spread process may be viewed as the product of the time-varying Poisson intensity and the recovery-rate process. Furthermore, they argue that the credit-spread process could also include a time-varying liquidity component which may be either positive or negative. In this paper, we simply refer to $\lambda$ as the credit-spread process, keeping in mind, however, that $\lambda$ may include both default-risk and liquidity components. Consequently, the term credit risk is used in a general sense throughout this paper, reflecting that variation in credit or swap spreads may be due to changes in either default risk or liquidity.

In applying this credit model to swaps, we are implicitly making two assumptions. First, we assume that there is no counterparty credit risk. This is consistent with recent papers by Grinblatt (2001), Duffie and Singleton (1997), and He (2000) that argue that the effects of counterparty credit risk on market swap rates should be negligible because of the standard marking-to-market or posting-of-collateral and haircut requirements almost universally applied in swap markets. ${ }^{4}$ Second, we make the relatively weak assumption that the credit risk inherent in the Libor rate (which determines the swap rate) can be modeled as the credit risk of a single defaultable entity. In actuality, the Libor rate is a composite of rates quoted by 16 banks and, as such, need not represent the credit risk of any particular bank. ${ }^{5}$ In this sense, the credit risk implicit in the swap curve can be viewed essentially as the average credit risk of the most representative banks providing quotations for Eurodollar balances. ${ }^{6}$

${ }^{3}$ In the Duffie and Singleton (1999) model, the recovery rate is linked to the value of the bond immediately prior to the default event. While this assumption has been criticized, the fact that Libor is computed from a set of banks that may change over time if some banks experience a deterioration in their credit rating argues that this assumption may be more defensible when applied to the swap curve.

${ }^{4}$ Even in the absence of these requirements, the effects of counterparty credit risk for swaps between similar counterparties are very small relative to the size of the swap spread. For example, see Cooper and Mello (1991), Sun, Sundaresan, and Wang (1993), Bollier and Sorensen (1994), Longstaff and Schwartz (1995), Duffie and Huang (1996), and Minton (1997).

${ }^{5}$ The official Libor rate is determined by eliminating the highest and lowest four bank quotes and then averaging the remaining eight. Furthermore, the set of 16 banks whose quotes are included in determining Libor may change over time. Thus, the credit risk inherent in Libor may be "refreshed" periodically as low credit banks are dropped from the sample and higher credit banks are added. The effects of this "refreshing" phenomenon on the differences between Libor rates and swap rates are discussed in Colin-Dufresne and Solnik (2001).

${ }^{6}$ For discussions about the economic role that interest-rate swaps play in financial mar- 
To model the discount bond prices $D(t, T)$ and $C(t, T)$, we next need to specify the dynamics of $r$ and $\lambda$. In doing this, we parallel the approach used by Duffie and Kan (1996), Duffie and Singleton (1997), Duffee (1999), Dai and Singleton (2000, 2001), and others by working within a general affine framework. In particular, we assume that the dynamics of $r$ and $\lambda$ are driven by a vector $X$ of five state variables, $X^{\prime}=\left[X_{1}, X_{2}, X_{3}, X_{4}, X_{5}\right]$. Following Dai and Singleton (2000), we assume that

$$
r=\delta_{0}+X_{1}+X_{2}+X_{3}+X_{4},
$$

where $\delta_{0}$ is a constant. Thus, the dynamics of the riskless term structure are driven by the first four state variables. This four-factor specification of the riskless term structure is consistent with recent evidence by Dai and Singleton (2001) and Duffee (2002) about the number of significant factors affecting Treasury yields. ${ }^{7}$

In modeling the dynamics of the spread $\lambda$, we assume that

$$
\lambda=\delta_{1}+\gamma r+X_{5},
$$

where $\delta_{1}$ and $\gamma$ are constants which may be positive or negative. Note that this specification allows the spread $\lambda$ to depend on the state variables driving the riskless term structure in both direct and indirect ways. Specifically, $\lambda$ depends directly on the first four state variables through the term $\gamma r$ in Eq. (4). Indirectly, however, the spread $\lambda$ may be correlated with the riskless term structure through correlations between $X_{5}$ and the other state variables.

The advantage of allowing for both a direct and an indirect relation between the spread $\lambda$ and the factors driving the riskless term structure is that it enables us to examine in more depth the determinants of swap spreads. For example, our approach allows us to examine whether the swap spread is an artifact of the difference in the tax treatment given to Treasury securities and Eurodollar deposits. Specifically, interest from Treasury securities is exempt from state income taxation while interest from Eurodollar deposits is not. Thus, if the spread $\lambda$ were determined entirely by the differential tax treatment, the parameter $\gamma$ would represent the marginal state tax rate

kets, see Bicksler and Chen (1986), Turnbull (1987), Smith, Smithson, and Wakeman (1988), Wall and Pringle (1989), Macfarlane, Ross, and Showers (1991), Sundaresan (1991), Litzenberger (1992), Sun, Sundaresan, and Wang (1993), Brown, Harlow, and Smith (1994), Minton (1997), Gupta and Subrahmanyam (2000), and Longstaff, Santa-Clara, and Schwartz (2001).

${ }^{7}$ Also see the empirical evidence in Litterman and Scheinkman (1991), Knez, Litterman, and Scheinkman (1994), Piazzesi (1999), and Longstaff, Santa-Clara, and Schwartz (2001) indicating the presence of at least three significant factors in term structure dynamics. 
of the marginal investor and might be on the order of .05 to .10. In contrast, structural models of default risk such as Merton (1974), Black and Cox (1976), Longstaff and Schwartz (1995) (also see Duffee (1998)), suggest that credit spreads should be inversely related to the level of $r$, implying a negative sign for $\gamma$. These hypotheses can be tested directly within our framework.

It is also important to note that this specification implies that all five state variables impact the swap curve. Thus, this framework should be viewed as providing a four-factor model of the Treasury curve and a five-factor model of the swap curve. Because of the direct and indirect dependence of $\lambda$ on the first four state variables, this framework should not be characterized as a single-factor model of the swap spread. Note also that we assume that the value of $\lambda$ is the same under both the objective and risk-neutral measures. This assumption is standard and allows the parameters of the model to be identified by maximum likelihood estimation. ${ }^{8}$

To close the model, we need to specify the dynamics of the five state variables driving $r$ and $\lambda$. Following Duffie and Kan (1996), Dai and Singleton (2000), and others, we assume that under the risk-neutral measure, the state variable vector $X$ follows the general Gaussian process,

$$
d X=-\beta X d t+\Sigma d B^{Q}
$$

where $\beta$ is a diagonal matrix, $B^{Q}$ is a vector of independent standard Brownian motions, $\Sigma$ is lower diagonal (with elements denoted by $\sigma_{i j}$ ), and the covariance matrix of the state variables $\Sigma \Sigma^{\prime}$ is of full rank and allows for general correlations among the state variables. As shown by Dai and Singleton (2000), this is most general Gaussian or $A_{5}(0)$ structure that can be defined under the risk neutral measure. Since $\lambda$ is linear in the state variables, this Gaussian specification implies that the spread could potentially be negative. There are several reasons why this assumption may be appropriate in this context. First, the process $\lambda$ reflects the differential credit between the swap and Treasury curves. While swap spreads have been uniformly positive in the U.S., swap spreads have occasionally been negative in other currencies, and are actually currently negative in Japan. Allowing $\lambda$ to take on negative values enables the model to be applied more generally. Secondly, $\lambda$ also reflects potential differences in liquidity. Again, while the liquidity of Treasury bonds has been very high historically, the liquidity of the swaps market is growing rapidly while the total notional amount of Treasury debt is not. Finally, Dai and Singleton (2001) argue that Gaussian models are more successful in capturing the dynamic behavior of risk premia in the class of affine models.

${ }^{8}$ Dai and Singleton (2002) show that if this assumption is relaxed, then the parameters of the model may not be identifiable from historical data and additional assumptions about objective default probabilities need to be appended to implement the model. 
To study how the market compensates investors over time for bearing credit risk, it is important to allow a fairly general specification of the market prices of risk in this affine $A_{0}(5)$ framework. Accordingly, we assume that the dynamics of $X$ under the objective measure are given by

$$
d X=-\kappa(X-\theta) d t+\Sigma d B^{P}
$$

where $\kappa$ is a diagonal matrix, $\theta$ is a vector, and $B^{P}$ is a vector of independent standard Brownian motions. This specification has the advantages of being both tractable and allowing for general time varying market prices of risk for each of state variables. ${ }^{9}$

Given the risk-neutral dynamics of the state variables, closed-form solutions for the prices of riskless zero-coupon bonds are given by

$$
D(t, T)=\exp \left(a(t)+b^{\prime}(t) X\right)
$$

where

$$
\begin{aligned}
a(t) & =-\delta_{0}(T-t)+\frac{1}{2} L^{\prime} \beta^{-1} \Sigma \Sigma^{\prime} \beta^{-1} L(T-t) \\
& -L^{\prime} \beta^{-1} \Sigma \Sigma^{\prime} \beta^{-2}\left(I-e^{-\beta(T-t)}\right) L+\sum_{i, j} \frac{1-e^{-\left(\beta_{i i}+\beta_{j j}\right)(T-t)}}{2 \beta_{i i} \beta_{j j}\left(\beta_{i i}+\beta_{j j}\right)}\left(\Sigma \Sigma^{\prime}\right)_{i j} L_{i} L_{j}, \\
b(t) & =\beta^{-1}\left(e^{-\beta(T-t)}-I\right) L
\end{aligned}
$$

and where $L^{\prime}=[1,1,1,1,0]$, and $I$ is the identity matrix. Similarly, the prices of risky zero-coupon bonds are given by

$$
C(t, T)=\exp \left(c(t)+d^{\prime}(t) X\right)
$$

\footnotetext{
${ }^{9}$ It is important to note, however, that even more general specifications for the market prices of risk are possible. In principle, for example, the diagonal matrix $\kappa$ could be generalized to allow nonzero off-diagonal terms. Our specification, however, already requires the estimation of ten market price of risk parameters which approaches the practical limits of our computational techniques. Adding more market price of risk parameters also raises the risk of creating identification problems.
} 
where

$$
\begin{aligned}
c(t) & =-\delta_{1}(T-t)+\frac{1}{2} M^{\prime} \beta^{-1} \Sigma \Sigma^{\prime} \beta^{-1} M(T-t) \\
& -M^{\prime} \beta^{-1} \Sigma \Sigma^{\prime} \beta^{-2}\left(I-e^{-\beta(T-t)}\right) M+\sum_{i, j} \frac{1-e^{-\left(\beta_{i i}+\beta_{j j}\right)(T-t)}}{2 \beta_{i i} \beta_{j j}\left(\beta_{i i} \beta_{j j}\right)}\left(\Sigma \Sigma^{\prime}\right)_{i j} M_{i} M_{j}, \\
d(t) & =\beta^{-1}\left(e^{-\beta(T-t)}-I\right) M,
\end{aligned}
$$

and where $M^{\prime}=[1+\gamma, 1+\gamma, 1+\gamma, 1+\gamma, 1]$. With these closed-form solutions, market price of bonds can be inverted to solve directly for the latent state variables.

\section{THE DATA}

Given this framework for modeling the swap and Treasury term structures, the next step is to estimate the parameters of the model using historical market data. In doing this, we use one of the most extensive sets of U.S. swap data available, covering the period from January 1988 to February 2002. This period includes most of the active history of the U.S. swap market.

The swap data for the study consist of weekly (Friday) observations of the threemonth Libor rate and midmarket constant maturity swap (CMS) rates for maturities of two, three, five, and ten years. These maturities represent the most liquid and actively-traded maturities for swap contracts. All of these rates are based on endof-trading-day quotes available in New York to insure comparability of the data. In estimating the parameters, we are careful to take into account daycount differences among the rates since Libor rates are quoted on an actual/360 basis while swap rates are semiannual bond equivalent yields. There are two sources for the swap data. The primary source is the Bloomberg system which uses quotations from a number of swap brokers. The data for Libor rates and for swap rates from the pre-1990 period are provided by Salomon Smith Barney. As an independent check on the data, we also compare the rates with quotes obtained from Datastream; the two sources of data are generally very consistent.

The Treasury data consists of weekly (Friday) observations of the constant maturity Treasury (CMT) rates published by the Federal Reserve in the H-15 release for maturities of two, three, five, and ten years. These rates are based on the yields of on-the-run Treasury bonds of various maturities and reflects the Federal Reserve's estimate of what the par or coupon rate would be for these maturities. CMT rates are widely used in financial markets as indicators of Treasury rates for the most-activelytraded-bond maturities. Since CMT rates are based heavily on the most-recentlyauctioned bonds for each maturity, CMT rates provide accurate estimates of yields 
for liquid on-the-run Treasury bonds. As such, these rates are more likely to reflect actual market prices than quotations for less-liquid off-the-run Treasury bonds. Since CMT rates are based on more-recently-issued bonds, however, they may incorporate the effects of any special repo financing that may be associated with these bonds. The possibility that these bonds may trade special in the repo market is taken into account explicitly in the estimation of the model. The sources of this data are the same as for swaps. Finally, data on three-month general collateral repo rates are provided by Salomon Smith Barney, who also provided us with a set of term special repo rates for June 30, 2000. Data for three-month Treasury bill rates are obtained from the Federal Reserve.

Table 1 presents summary statistics for the swap and Treasury data, as well as the corresponding swap spreads. In this paper, we define the swap spread to be the difference between the CMS rate and the corresponding-maturity CMT rate. Fig. 1 plots the two-year, three-year, five-year, and ten-year swap spreads over the sample period. As shown, swap spreads average between 40 and 60 basis points during the sample period, with standard deviations on the order of 20 to 25 basis points. The standard deviations of weekly changes in swap spreads are only on the order of six to eight basis points. Note, however, that there are weeks during which swap spreads narrow or widen by as much as 45 basis points. In general, swap spreads are less serially correlated than the interest rates. The first difference of swap spreads, however, displays significantly more negative serial correlation. This implies that there is a strong mean reverting component to swap spreads.

\section{ESTIMATING THE TERM STRUCTURE MODEL}

In this section, we describe the empirical approach used in estimating the term structure model and report the maximum likelihood parameter estimates. The empirical approach closely parallels that of the recent papers by Duffie and Singleton (1997), Dai and Singleton (2000), and Duffee (2002). This approach also draws on other papers in the empirical term structure literature such as Longstaff and Schwartz (1992), Chen and Scott (1993), Pearson and Sun (1994), Duffee (1999), and many others.

In this five-factor model, the parameters of both the objective and risk-neutral dynamics of the state variables need to be estimated. In addition, we need to solve for the value of the state variable vector $X$ for each of the 734 weeks in the sample period. At each date, the information set consists of observations of four points along the Treasury curve and five points along the swap curve. Specifically, we use the CMT2, CMT3, CMT5 and CMT10 rates for the Treasury curve, and the three-month Libor, CMS2, CMS3, CMS5, and CMS10 rates for the swap curve. Since the model involves only five state variables, using nine observations at each date provides us with significant additional cross-sectional pricing information from which the parameters of the risk-neutral dynamics can be more precisely identified. 
We focus first on how the five values of the state variables are determined. Similar to Chen and Scott (1993), Duffie and Singleton (1997), Dai and Singleton (2000), Duffee (2002), and others, we solve for the value of $X$ by assuming that specific rates are observed without error each week. In particular, we assume that the CMT2, CMT3, and CMT10 rates, along with the three-month Libor and CMS10 rates, are observed without error. These rates include the shortest and longest maturity rates along both curves and are among the most-liquid maturities quoted, and hence, the most likely to be observed with a minimum of error. Note that Libor is given simply from the expression for a risky zero-coupon bond,

$$
\text { Libor }=\frac{a}{360}\left[\frac{1}{C(t, t+1 / 4)}-1\right] \text {, }
$$

where $a$ is the actual number of days during the next three months. Since CMT and CMS rates represent par rates, they are also easily expressed as explicit functions of the values of riskless and risky zero coupon bonds,

$$
\begin{aligned}
& C M T_{T}=2\left[\frac{1-D(t, t+T)}{\sum_{i=1}^{2 T} D(t, t+i / 2)}\right], \\
& C M S_{T}=2\left[\frac{1-C(t, t+T)}{\sum_{i=1}^{2 T} C(t, t+i / 2)}\right] .
\end{aligned}
$$

Given a parameter vector, we can then invert the closed-form expressions for these five rates to solve for the corresponding values of the state variables using a standard nonlinear optimization technique. While this process is straightforward, it is computationally very intensive since the inversion must be repeated for every trial value of the parameter vector utilized by the numerical search algorithm in maximizing the likelihood function.

To define the log likelihood function, let $R_{1, t}$ be the vector of the five rates assumed to be observed without error at time $t$, and let $R_{2, t}$ be the vector of the remaining four observed rates. Using the closed-form solution, we can solve for $X_{t}$ from $R_{1 t}$

$$
X_{t}=h\left(R_{1, t}, \Theta\right)
$$

where $\Theta$ is the parameter vector. The conditional $\log$ likelihood function for $X_{t+\Delta t}$ is

$$
-\frac{1}{2}\left(\left(X_{t+\Delta t}-\theta-K\left(X_{t}-\theta\right)\right)^{\prime} \Omega^{-1}\left(X_{t+\Delta t}-\theta-K\left(X_{t}-\theta\right)\right)+\ln |\Omega|\right),
$$


where $K$ is a diagonal matrix with $i$-th diagonal term $e^{-\kappa_{i i} \Delta t}$, and $\Omega$ is a matrix with $i j$-th term given by

$$
\Omega_{i j}=\frac{1-e^{-\left(\kappa_{i i}+\kappa_{j j}\right) \Delta t}}{\kappa_{i i}+\kappa_{j j}}\left(\Sigma \Sigma^{\prime}\right)_{i j} .
$$

Let $\epsilon_{t+\Delta t}$ denote the vector of differences between the observed value of $R_{2, t+\Delta t}$ and the value implied by the model. ${ }^{10}$ Assuming that the $\epsilon$ terms are independently distributed normal variables with zero means and variances $\eta_{i}^{2}$, the log likelihood function for $\epsilon_{t+\Delta t}$ is given by

$$
-\frac{1}{2} \epsilon_{t+\Delta t}^{\prime} \Sigma_{\epsilon}^{-1} \epsilon_{t+\Delta t}-\frac{1}{2} \ln \left|\Sigma_{\epsilon}\right|
$$

where $\Sigma_{\epsilon}$ is a diagonal matrix with diagonal elements $\eta_{i}^{2}, i=1, \ldots, 4$.

Since $X_{t+\Delta t}$ and $\epsilon_{t+\Delta t}$ are assumed to be independent, the log likelihood function for $\left[X_{t+\Delta t}, \epsilon_{t+\Delta t}\right]^{\prime}$ is simply the sum of Eqs. (13) and (14).

The final step in specifying the likelihood function consists of changing variables from the vector $\left[X_{t}, \epsilon_{t}\right]^{\prime}$ of state variables and error terms to the vector $\left[R_{1, t}, R_{2, t}\right]^{\prime}$ of rates actually observed. It is easily shown that the determinant of the Jacobian matrix is given by $\left|J_{t}\right|=\left|\frac{\partial h\left(R_{1, t}\right)}{\partial R_{1, t}^{\prime}}\right|$. Summing over all observations gives the log likelihood function for the data

$$
\begin{aligned}
& -\frac{1}{2} \sum_{t=1}^{T-1}\left[\left(X_{t+\Delta t}-\theta-K\left(X_{t}-\theta\right)\right)^{\prime} \Omega^{-1}\left(X_{t+\Delta t}-\theta-K\left(X_{t}-\theta\right)\right)\right. \\
& \left.\quad+\ln |\Omega|+\epsilon_{t+\Delta t}^{\prime} \Sigma_{\epsilon}^{-1} \epsilon_{t+\Delta t}+\ln \left|\Sigma_{\epsilon}\right|+2 \ln \left|J_{t}\right|\right]
\end{aligned}
$$

Given this specification, likelihood function depends explicitly on 37 parameters.

From this log likelihood function, we now solve directly for the maximum likelihood parameter estimates using a standard nonlinear optimization algorithm. In doing this, we initiate the algorithm at a wide variety of starting values to insure that the global maximum is achieved. Furthermore, we check the results using an alternative genetic algorithm which has the property of being less susceptible to finding local minima. These diagnostic checks confirm that the algorithm converges to the

${ }^{10}$ We assume that the $\epsilon$ terms are independent. In actuality, the $\epsilon$ terms could be correlated. As is shown later, however, the variances of the $\epsilon$ terms are very small and the assumption of independence is unlikely to have much effect on the estimated model parameters. 
global maximum and that the parameter estimates are robust to perturbations of the starting values.

Table 2 reports the maximum likelihood parameter estimates and their asymptotic standard errors. As shown, there are clear differences between the objective and risk-neutral parameters. These differences have major implications for the dynamics of the key variables $r$ and $\lambda$ which we consider in the next two sections. The differences themselves reflect the market prices of risk for the state variables and also have important implications for the expected returns from bearing credit and liquidity risk. We note that the $\beta$ and $\kappa$ parameters are all estimated to be positive; the estimation procedure does not constrain these parameters to be positive. One key result that emerges from the maximum likelihood estimation is that the five-factor model fits the data well, at least in its cross-sectional dimension. For example, the standard deviations of the pricing errors for the CMS2, CMS3, CMS5, and CMT5 rates (given by $\eta_{1}$, $\eta_{2}, \eta_{3}$, and $\eta_{4}$, respectively) are $12.2,9.0,6.4$, and 6.0 basis points respectively. These errors are fairly small and are on the same order of magnitude as those reported in Dai and Singleton (1997) and Duffee (2002). Note, however, that we are estimating both the Treasury and swap curves simultaneously. In addition, with the exception of a few of the parameters of $\Sigma$, all of the parameters of the model are statistically significant based on their asymptotic standard errors.

Table 3 reports the correlation matrix for the state variables implied by the maximum likelihood estimates of the parameters defining $\Sigma$. As shown, a number of the correlations are negative. As pointed out by Duffee (2002) and Dai and Singleton (2002), it is not possible to capture the empirically-observed humped term structure of interest rate volatility within an affine model unless there are negative correlations among some of the factors. Thus, our results are consistent with these empirical properties.

\section{THE IMPLIED FINANCING RATE}

The instantaneous riskless rate $r$ plays a central role in many continuous-time term structure models. In addition to being the shortest-maturity rate, $r$ can also be viewed as the cost of borrowing on short-term riskless loans such as those fully secured by riskless Treasury bond collateral. Traditionally, the cost of riskless borrowing is equated to the Treasury-bill rate since this is the rate at which the U.S. Treasury can borrow short-term funds. Among practitioners, however, the Treasury-bill rate is generally viewed as a noisy measure of the true riskless rate (see also recent academic work by Duffee (1996)). The reason for this is the widespread belief that the extreme liquidity of Treasury bills makes them worth slightly more than the present value of their cash flows, and hence, that Treasury-bill rates can represent downward biased estimates of the true cost of riskless borrowing. Some recent papers (for example, Longstaff (2000)) suggest considering general collateral Treasury repo rates as an 
alternative measure of the riskless rate. The rationale for this measure is that repo loans that are overcollateralized by default-free Treasury bonds are essentially riskless short-term loans. Because repo loans are financial contracts rather than securities, however, they may be less affected by liquidity events such as short squeezes (although there are many examples of illiquid financial contracts).

A useful feature of our approach is that we can solve for the value of $r$ endogenously and then contrast it with market rates. This allows us to explore directly the question of whether the implied value of $r$ more closely resembles Treasury-bill rates or repo rates. In this model, the implied rate $r$ represents the cost of carrying a position in the longer-term Treasury bonds defining the CMT rates. If these longer-term bonds do not have special liquidity value, then $r$ should represent the riskless interest rate for the market. On the other hand, if longer-term Treasury bonds have liquidity value, then the estimated value of $r$ takes on the interpretation of a special repo rate in the sense of Duffie (1996). Specifically, since $r$ is implied from the cross section of CMT rates (and from the swap rates), $r$ represents the average or typical short-term special repo rate for the on-the-run bonds in the sample. ${ }^{11}$ In this case, $r$ may then be less than the true riskless rate. To reflect the unique role that $r$ plays in this model, we designate $r$ the implied financing rate.

To make estimates of the implied financing rate comparable with the three-month general collateral repo and Treasury-bill rates in the sample, we redefine the implied financing rate slightly to be the yield implied by a three-month riskless zero coupon bond. ${ }^{12}$ Using the maximum likelihood parameter values, the values of the state variables are implied from the data as described previously. Given the values of the state variables, the value of the riskless bond is obtained directly from the closed-form expression in Eq. (7). Table 4 reports summary statistics for the three-month general collateral repo rates, implied financing rates, and Treasury-bill rates along with the spreads between these rates. Fig. 2 graphs the difference between the implied financing rate and the Treasury-bill rate, and the difference between the repo rate and the implied financing rate.

As shown, the implied financing rate generally lies between the general collateral repo rate and the Treasury-bill rate. On average, the implied financing rate is 8.0 basis points below the repo rate, but 27.6 basis points above the Treasury-bill rate. The median implied financing rate is 2.9 basis points below the median repo rate, but

${ }^{11}$ We are using a slightly broader interpretation of the special repo rate since special repo rates are typically associated with a specific Treasury bond. The advantage of this approach, however, is that since these implied special repo rates are based on the dynamics of $r$, they reflect not only the current liquidity of the bonds, but also the possibility of future increases in their liquidity. Thus, this interpretation lends itself well to comparisons with term special repo rates.

${ }^{12}$ See Chapman, Long, and Pearson (1999) for a discussion of the effects of using three-month rates as a proxy for instantaneous rates. 
27.5 basis points above the median Treasury-bill rate. These results are consistent with the view that the general collateral repo rate may be closer to the actual riskless rate than the Treasury-bill rate.

The spread between the implied financing rate and the Treasury-bill rate can be interpreted as a measure of the relative liquidity of Treasury bills and on-the-run Treasury bonds. As shown in Fig. 2, this spread is typically positive, suggesting that Treasury bills tended to be more liquid than Treasury bonds during much of the sample period. During the 1990-93 period, however, the liquidity of Treasury bonds and bills appears to converge. After the hedge fund crisis of 1998, the implied financing rate actually dips below the Treasury-bill rate, which suggests that longer-term on-the-run Treasury bonds may have become more liquid that Treasury bills. This could possibly be related to the fact that the U.S. Treasury no longer auctions one-year Treasury bills on a regular basis.

Note that our estimates of this liquidity spread are consistent with those estimated by Amihud and Mendelson (1991) and Kamara (1994) from the differences between the yields on off-the-run Treasury notes and Treasury bills. For example, Amihud and Mendelson find that the spread between off-the-run Treasury notes and T-bills averages 42.8 basis points. Kamara reports an average difference between Treasury note and bill yields of 34 basis points. Since we use on-the-run bonds while Amihud and Mendelson and Kamara use off-the-run bonds in computing the liquidity premium in Treasury bills, one would expect our estimate to be less than theirs by the amount of the liquidity difference between on-the-run and off-the-run Treasury bonds. Subtracting our estimate of 27.6 basis points from their estimates implies a liquidity difference between off-the-run and on-the-run bonds of 6.4 to 15.2 basis points. While we acknowledge that that comparing spreads from different studies (calculated using different data and time periods) is far from a rigorous analysis, it is intriguing that these estimates are very consistent with the evidence from term repo rates to be presented later in this section.

If one is willing to equate the general collateral repo rate with the riskless rate, then the difference between the repo rate and the implied financing rate could be given a simple interpretation of the average implied specialness of the on-the-run Treasury bonds used to compute CMT rates. Fig. 2 shows that this implied specialness varies significantly over time. During the first part of the sample period, the implied specialness is as high as 40 basis points, suggesting that the prices of Treasury bonds have a large liquidity component. During the 1994-1998 period, the implied specialness of the Treasury bonds essentially disappears and the implied financing rate approximates the general collateral repo rate. After the hedge-fund crisis of 1998, however, the implied specialness of the bonds increases dramatically, reaching a high of more than 75 basis points near the end of the sample period.

To provide a simple "back-of-the-envelope" estimate of the size of the liquidity or specialness component in the prices of on-the-run Treasury bonds, we do the following. 
First, we denote the implied specialness (general collateral repo rate - the implied financing rate) by $S_{t}$, and assume that $S_{t}$ follows a standard Ornstein-Uhlenbeck process. Estimating the parameters of this process by maximum likelihood gives the following dynamic specification for $S_{t}$,

$$
d S=5.91812(.000842-S) d t+.00799 d B
$$

where $B$ is a standard Brownian motion. For a zero-coupon Treasury bond with maturity $T$, the present value benefit or specialness premium from being able to borrow at the special repo rate rather than the general repo rate equals

$$
D(T)-D(T) E\left[\exp \left(-\int_{0}^{T} S_{t} d t\right)\right],
$$

under the assumptions that $B$ is independent of the other Brownian motions in the term structure model and that the market price of risk for $S$ is zero. Evaluating this expectation (using the Vasicek (1977) interest rate model) allows us to obtain estimates of the size of the liquidity or specialness premia in the prices of the Treasury bonds. Summary statistics for these premia are reported in Table 5.

As shown, the value of liquidity or specialness premium in the prices of on-therun Treasury bonds can be substantial. For the two-year Treasury note, the premium ranges from about four cents to 14 cents during the sample period per $\$ 100$ notional amount, which translates roughly to a two to seven basis point effect on the yield. Thus, there is significant time variation in the value of the premium. For the tenyear Treasury note, the premium was typically in excess of 42 cents per $\$ 100$ notional or roughly six basis points in terms of yield to maturity. During the latter portion of the sample period, the premium was as high as 57 cents, or eight basis points of yield. These results indicate that the value of liquidity can represent an important time-varying component of the value of a Treasury bond.

As an additional diagnostic for the estimated specialness premia, we also use a set of term special repo rates provided to us by Salomon Smith Barney. This data set reports the longest term special repo rates for individual Treasury bonds available in the market as of June 30, 2000, along with the general collateral repo rate for the same term. The implied premium per $\$ 100$ value of the bond is given by simply taking the difference between the general collateral and special repo rates and multiplying by the term of the repo measured in years. This makes clear that the value of the specialness premium can be viewed as the interest savings an investor who finances his purchase of the bond would receive by being able to finance at the special repo rate rather than the general collateral repo rate. Table 6 reports the special and general collateral rates for the bonds with maturities of ten years or less along with the implied specialness 
premia. The two-year, five-year, and ten-year on-the-run bonds are denoted by an asterisk.

As shown in Table 6, a number of Treasury bonds trade special in the repo market. For many of these bonds, the difference between the term special and general collateral repo rates is small, and the implied specialness premium is likewise small. For the on-the-run bonds, however, the value of the specialness premia is substantial. In particular, the specialness premia for the two-year, five-year, and ten-year on-therun bonds given in Table 6 are 8.0 cents, 50.5 cents, and 64.3 cents respectively. ${ }^{13}$ This agrees well with the average implied specialness premia reported in Table 5. Furthermore, as discussed earlier, these estimates of the liquidity premia in on-the-run special bonds are also in broad agreement with the estimated liquidity premia in Treasury bills relative to on-the-run bonds shown in Table 5 and the average liquidity premia for Treasury bills relative to off-the-run bonds reported by Amihud and Mendelson (1991) and Kamara (1994) (see also Boudoukh and Whitelaw (1993), Longstaff (1995), Jordan and Jordan (1997), Buraschi and Menini (2001), and Krishnamurthy (2001)). This provides additional evidence that the model is capturing key features of the Treasury and swap term structures. ${ }^{14}$

\section{THE SPREAD PROCESS}

The spread process $\lambda$ plays a particularly important role in the Duffie and Singleton (1997) credit modeling framework. Recall that in this framework, the spread $\lambda$ may consist of both default-risk and liquidity components. Since the Libor rate is fitted exactly in the maximum likelihood estimation, the implied spread $\lambda$ can be thought of as the difference between the Libor rate and the implied financing rate. From Eqs. (3) and (4), $\lambda$ is a function of all five state variables. Table 2 reports that the maximum likelihood estimate of the parameter $\gamma$ is -.07126 , which implies that there is a strong negative relation between the level of $\lambda$ and the level of the riskless rate $r$. This relation is consistent with the negative relation between rates and spreads implied by a number of fundamental models of credit spreads including Merton (1974), Black and Cox (1976), and Longstaff and Schwartz (1995) and documented by Duffee (1998) and others. As discussed earlier, an additional influence on the value of $\gamma$ could be taxation, since Treasury bills are not taxable for state income tax purposes while Libor cash flows are. That $\gamma$ is negative, however, argues against the hypothesis that swap spreads are primarily an artifact of differential taxation.

${ }^{13}$ There is no on-the-run three-year bond on June 30, 2000 because the Treasury had previously stopped auctioning three-year bonds.

${ }^{14}$ Conversations with market practitioners indicate that there are occasional periods during which the specialness premia for some on-the-run Treasury issues implied by market term special repo rates are on the order of twice those shown in Table 6 . 
Fig. 3 graphs the time series of $\lambda$ for the sample period. As illustrated, the spread $\lambda$ varies significantly over time. For example, at the beginning of the sample period, the spread is on the order of 80 basis points. During the latter 1990s, however, the spread decreases significantly and becomes nearly zero. The period during which the spread is nearly zero coincides with the period in which there is little apparent liquidity component in Treasury bonds as measured by the implied specialness estimate. This suggests that this period may represent a time when the market viewed both the liquidity of the swap market as identical to that of Treasury bonds and the probability that banks quoting Libor rates could default as essentially zero. Although the model allows the spread to become negative, relatively few observations are actually (slightly) negative.

In theory, the spread $\lambda$ could include both default-risk and liquidity components. Although there is no simple way to decompose the spread into these two components, it is interesting to compare the spread with several variables which may be correlated with these components. For example, the spread between the general repo rate and the implied financing rate can be viewed as a proxy for Treasury liquidity. Similarly, the spread between the Libor rate and the general repo rate should contain information about the default risk of banks quoting Libor rates. To explore this, Fig. 4 presents scatterdiagrams of the credit spread against these two variables. As illustrated, the correlation between the spread and the proxy for liquidity is much higher than the correlation between the spread and the proxy for default risk. In particular, the correlation of the spread with the default-risk proxy is .126 while the correlation of the spread with the liquidity proxy is .830. Furthermore, the correlation of weekly changes in the spread with changes in in the default-risk proxy is -.115 while the correlation of weekly changes in the spread with changes in the liquidity proxy is .558. Taken together, these results are supportive of the view that much of the variation in spreads is driven by changes in liquidity.

\section{THE MARKET PRICE OF CREDIT RISK}

A major objective of this paper is to examine how the market prices the credit risk in interest rate swaps. To this end, we focus on the premia that are incorporated into the expected returns of bonds implied by the estimated term structure model. These premia are given directly from the differences between the objective and risk-neutral parameters of the model.

To provide some perspective for these results, however, it is useful to also examine the implications of the model for the term premia in Treasury bond prices. Applying Ito's Lemma to the closed-form expression for the value of a riskless zero-coupon bond given in Eq. (7) results in the following expression for its instantaneous expected return 


$$
\left.r+b^{\prime}(t)\left((\beta-\kappa) X_{t}+\kappa \theta\right)\right)
$$

The first term in this expression is the riskless rate and the sum of the remaining terms is the instantaneous term premium for the bond. This term premium is time varying since it depends explicitly on the state variables. To solve for the unconditional term premium, we take the expectation over the objective measure of the state variables which gives $b^{\prime}(t) \beta \theta$.

Now applying Ito's Lemma to the closed-form expression for the price of the risky zero-coupon bond given in Eq. (8) leads to the following expression for the instantaneous expected return

$$
\left.r+d^{\prime}(t)\left((\beta-\kappa) X_{t}+\kappa \theta\right)\right)
$$

The first term in this expression is again the instantaneous risky rate. The sum of the remaining terms can be interpreted as the combined term premium and credit premium. To solve for the credit premium separately, we simply take the difference between the expected return of a risky zero-coupon bond and the expected return on a riskless zero-coupon bond with the same maturity. As before, the credit premium is time varying through its dependence on the state variables. Taking the expectation with respect to the objective measure for the state variables and subtracting the expression for the unconditional term premium gives $(d(t)-b(t))^{\prime} \beta \theta$.

Focusing first on the unconditional premia, Table 7 reports the unconditional term premia for riskless zero-coupon bonds with maturities ranging from one to ten years. Table 7 also reports the unconditional credit premia for risky zero-coupon bonds with the same maturities. These unconditional premia are also graphed in Fig. 5. As shown, the mean term premia are positive and monotonically increasing functions of time to maturity. Mean term premia range from about 97 basis points for a one-year horizon to about 321 basis points for a ten-year horizon. These estimates of unconditional term premia are similar to those reported by Fama (1984), Fama and Bliss (1987), and others.

Table 7 and Fig. 5 also show that unconditional credit premia are positive and increasing functions of maturity. The mean credit premium for a one-year horizon is only 0.1 basis points. Thus, there is very little compensation on average for bearing short-term credit risk. At longer horizons, however, the mean credit premium is much larger. For example, the mean credit premium for a ten-year horizon is 45 basis points. The convex shape of the unconditional credit premium curve indicates that investors require sharply higher credit premia as the maturity of the bond increases. This pattern contrasts with that observed for the unconditional term premia.

To give some sense of the time variation in term and credit premia, Fig. 6 graphs these premia for a ten-year maturity zero-coupon bond. As illustrated, the term 
premium displays a significant amount of variation. The term premium is usually positive, but has generally tended downward throughout the sample period and is significantly negative at the end of the sample period.

The time series of the credit premium displays a number of surprising features. Recall that the average credit premium for a ten-year horizon is about 45 basis points. Fig. 6 shows that the conditional credit premium varies significantly over time and is often large in absolute terms. Most surprisingly, the credit premium is negative for nearly one half of the sample period. The credit premium first becomes negative in approximately 1992 and remains generally negative until the fall of 1998. This is about when the Russian government defaulted on a large issue of its ruble-denominated debt. Despite the variation, however, the credit premium appears to be less volatile than the term premium. Although not shown, a very similar pattern holds for credit premia in bonds with shorter maturities.

\section{CONCLUSION}

This paper examines how the market prices the credit and liquidity risk inherent in interest rate swaps relative to Treasury bonds. A number of key results emerge from this analysis. For example, we find that on-the-run Treasury bonds have a significant liquidity component to their value. This liquidity component can be as much as 0.57 percent of the notional amount of a ten-year Treasury bond. The value of this liquidity component varies significantly over time. In addition, we find that the market prices the credit risk of swaps. The market price of credit risk, however, varies over time and was occasionally negative for during the 1990s.

There are a number of possible extensions to this research. For example, the approach of solving for the implied financing rate could be applied to the term structures for corporate bond issuers and then used to identify the liquidity components of their spreads. ${ }^{15}$ One major puzzle is why the credit premia implicit in swap spreads were negative during the 1990s, and only became significantly positive again after the hedge-fund crisis of 1998. Certainly, these results are difficult to reconcile with a view of the market in which investors are aware of the historical variability in swap spreads and where expected returns compensate investors for their exposure to risk. A possible resolution of this puzzle may be that most of the credit risk reflected in swap spreads may actually represent the liquidity risk of Treasury bonds. From this perspective, Treasury bonds may be subject to a unique risk which does not affect pure contracts such as swaps, and may be priced accordingly in the market. Clearly, further research is necessary to resolve this issue.

$\overline{{ }^{15} \text { Huang and Huang (2000) }}$ focus on the estimation of the liquidity components in corporate bond prices. 


\section{REFERENCES}

Amihud, Y. and H. Mendelson, 1991, Liquidity, Maturity, and the Yields on U. S. Treasury Securities, The Journal of Finance 46, 1411-1425.

Bicksler, J. and A. H. Chen, 1986, An Economic Analysis of Interest Rate Swaps, Journal of Finance 41, 645-655.

Black, F. and J. Cox, 1976, Valuing Corporate Securities: Some Effects of Bond Indenture Provisions, The Journal of Finance 31, 351-367.

Bollier, T., and E. Sorensen, 1994, Pricing Swap Default Risk, Financial Analysts Journal, May-June, 23-33.

Boudoukh, J. and R. Whitelaw, 1993, Liquidity as a Choice Variable: A Lesson from the Japanese Government Bond Market, The Review of Financial Studies 6, 265-292.

Brown, K., W. Harlow, and D. Smith, 1994, An Empirical Analysis of Interest Rate Swap Spreads, Journal of Fixed Income, March, 61-78.

Buraschi, A. and D. Menini, 2001, Liquidity Risk and Special Repos: How Well Do Forward Repo Spreads Price Future Specialness, Journal of Financial Economics, forthcoming.

Chapman, D., J. Long, Jr., and N. Pearson, 1999, Using Proxies for the Short Rate: When are Three Months Like an Instant?, Review of Financial Studies 12, 763-806.

Chapman, D., and N. Pearson, 2001, Recent Advances in Estimating Term-Structure Models, Financial Analysts Journal July/August, 77-95.

Chen, R. R. and L. Scott, 1993, Maximum Likelihood Estimation for a Multifactor Equilibrium Model of the Term Structure of Interest Rates, Journal of Fixed Income $3,14-31$.

Collin-Dufresne, P. and B. Solnik, 2001, On the Term Structure of Default Premia in the Swap and Libor Markets, The Journal of Finance, forthcoming.

Cooper, I. and A. Mello, 1991, The Default Risk on Swaps, The Journal of Finance 46, 597-620.

Dai, Q. and K. Singleton, 2000, Specification Analysis of Affine Term Structure Models, The Journal of Finance 55, 1943-1978.

Dai, Q. and K. Singleton, 2001, Expectations Puzzles, Time-Varying Risk Premia, and Dynamic Models of the Term Structure, Journal of Financial Economics, forthcoming. 
Dai, Q. and K. Singleton, 2002, Term Structure Dynamics in Theory and Reality, Working Paper, Stanford University.

Duffee, G., 1996, Idiosyncratic Variation of Treasury Bill Yield Spreads, Journal of Finance 51, 527-552.

Duffee, G., 1998, The Relation Between Treasury Yields and Corporate Bond Yield Spreads, Journal of Finance 53, 2225-2241.

Duffee, G., 1999, Estimating the Price of Default Risk, The Review of Financial Studies $12,197-226$.

Duffee, G., 2002, Term Premia and Interest Rate Forecasts in Affine Models, Journal of Finance 57, 405-443.

Duffie, D., 1996, Special Repo Rates, The Journal of Finance 51, 493-526.

Duffie, D. and M. Huang, 1996, Swap Rates and Credit Quality, The Journal of Finance 51, 921-949.

Duffie, D. and R. Kan, 1996, A Yield-Factor Model of Interest Rates, Mathematical Finance 6, 379-406.

Duffie, D. and J. Liu, 2001, Floating-Fixed Credit Spreads, Financial Analysts Journal 57, May/June, 76-87.

Duffie, D., L. Pedersen, K. Singleton, 2000, Modeling Sovereign Yield Spreads: A Case Study of Russian Debt, Working paper, Stanford University.

Duffie, D. and K. Singleton, 1997, An Econometric Model of the Term Structure of Interest Rate Swap Spreads, The Journal of Finance 52, 1287-1321.

Duffie, D. and K. Singleton, 1999, Modeling Term Structures of Defaultable Bonds, The Review of Financial Studies 12, 687-720.

Fama, E. , 1984, Term Premiums in Bond Returns, Journal of Financial Economics 13, 529-546.

Fama, E. and R. Bliss, 1987, The Information in Long-Maturity Forward Rates, American Economic Review 77, 680-692.

Grinblatt, M., 2001, An Analytical Solution for Interest Rate Swap Spreads, Review of International Finance, forthcoming.

Gupta, A. and M. Subrahmanyam, 2000, An Empirical Investigation of the Convexity Bias in the Pricing of Interest Rate Swaps, Journal of Financial Economics 55, 239-279. 
He, H., 2000, Modeling Term Structures of Swap Spreads, Working paper, Yale University.

Huang, J., and M. Huang, 2000, How Much of the Corporate-Treasury Yield Spread is Due to Credit Risk?: Results from a New Calibration Approach, Working paper, Stanford University.

Jordan, B. and S. Jordan, 1997, Special Repo Rate: An Empirical Analysis, The Journal of Finance 52, 2051-2072.

Kamara, A., 1994, Liquidity, Taxes, and Short-Term Treasury Yields, Journal of Financial and Quantitative Analysis 29, 403-417.

Knez, P., R. Litterman, and J. Scheinkman, 1994, Explorations into Factors Explaining Money Market Returns, The Journal of Finance 49, 1861-1882.

Krishnmurthy, A., 2001, The Bond/Old-Bond Spread, Working paper, Northwestern University.

Litterman, R. and J. Scheinkman, 1991, Common Factors Affecting Bond Returns, The Journal of Fixed Income 1, 54-61.

Litzenberger, R., 1992, Swaps: Plain and Fanciful, The Journal of Finance 42, 831-850.

Longstaff, F., 2000, The Term Structure of Very Short-Term Rates: New Evidence for the Expectations Hypothesis, Journal of Financial Economics 58, 397-415.

Longstaff, F. and E. Schwartz, 1992, Interest Rate Volatility and the Term Structure: A Two-Factor General Equilibrium Model, The Journal of Finance 47, 1259-1282.

Longstaff, F. and E. Schwartz, 1995, A Simple Approach to Valuing Risky Fixed and Floating Rate Debt, The Journal of Finance 50, 789-819.

Longstaff, F., P. Santa-Clara, and E. S. Schwartz, 2001, The Relative Valuation of Caps and Swaptions: Theory and Empirical Evidence, Journal of Finance 56, 2067-2109.

Macfarlane, J., D. Ross, and J. Showers, 1991, The Interest Rate Swap Market: Yield Mathematics, Terminology, and Conventions, in Interest Rate Swaps, ed. Carl R. Beidleman, (Business One Irwin, Homewood, IL).

Merton, R. C., 1974, On the Pricing of Risky Debt: The Risk Structure of Interest Rates, The Journal of Finance 29, 449-470.

Minton, B., 1997, An Empirical Examination of Basic Valuation Models for Plain Vanilla U.S. Interest Rate Swaps, Journal of Financial Economics 44, 251-277.

Pearson, N. and T-S. Sun, 1994, An Empirical Examination of the Cox, Ingersoll, and 
Ross Model of the Term Structure of Interest Rates Using the Method of Maximum Likelihood, The Journal of Finance 54, 929-959.

Piazzesi, M., 1999, An Econometric Model of the Yield Curve with Macroeconomic Jump Effects, Working paper, UCLA.

Smith, C. W., C. W. Smithson, and L. M. Wakeman, 1988, The Market for Interest Rate Swaps, Financial Management 17, 34-44.

Sun, T., S. M. Sundaresan, and C. Wang, 1993, Interest Rate Swaps: An Empirical Investigation, Journal of Financial Economics 36, 77-99.

Sundaresan, S. M., 1991, Valuation of Swaps, in Sarkis J. Khoury, ed., Recent Developments in International Banking and Finance, vol 5, New York: Elsevier Science Publishers.

Sundaresan, S. M., 1994, An Empirical Analysis of U.S. Treasury Auctions: Implications for Auction and Term Structure Theories, Journal of Fixed Income, 35-50.

Turnbull, S., 1987, Swaps: Zero-Sum Game?, Financial Management 16, 15-21.

Vasicek, O., 1977, An Equilibrium Characterization of the Term Structure, Journal of Financial Economics 5, 177-188.

Wall, L. D. and J. J. Pringle, 1989, Alternative Explanations of Interest Rate Swaps: A Theoretical and Empirical Analysis, Financial Management 16, 15-21 


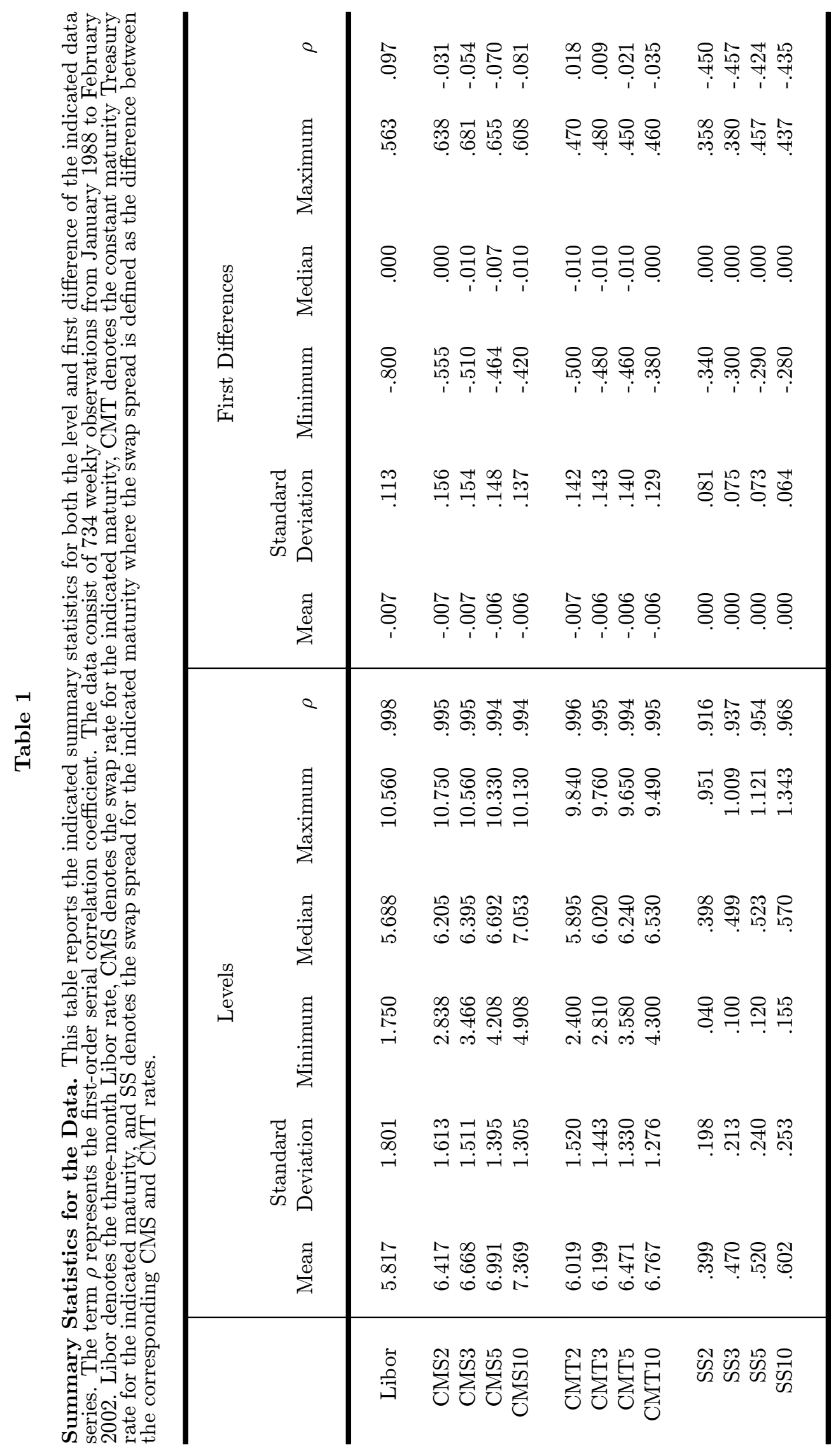


Table 2

Maximum Likelihood Estimates of the Model Parameters. This table reports the maximum likelihood estimates of the parameters of the five-factor term structure model along with their asymptotic standard errors. The asymptotic standard errors are based on the inverse of the information matrix computed from the Hessian matrix for the log likelihood function.

\begin{tabular}{|c|c|c|}
\hline Parameter & Value & Std. Error \\
\hline $\begin{array}{l}\beta_{1} \\
\beta_{2} \\
\beta_{3} \\
\beta_{4} \\
\beta_{5}\end{array}$ & $\begin{array}{r}15.89001 \\
1.03109 \\
.29298 \\
.00004 \\
.00487\end{array}$ & $\begin{array}{r}1.12163 \\
.01902 \\
.00669 \\
.00001 \\
.00028\end{array}$ \\
\hline $\begin{array}{l}\kappa_{1} \\
\kappa_{2} \\
\kappa_{3} \\
\kappa_{4} \\
\kappa_{5}\end{array}$ & $\begin{array}{r}10.12189 \\
11.67224 \\
1.78303 \\
.46752 \\
1.61688\end{array}$ & $\begin{array}{l}.78817 \\
.88389 \\
.42228 \\
.14111 \\
.38056\end{array}$ \\
\hline $\begin{array}{c}\theta_{1} \\
\theta_{2} \\
\theta_{3} \\
\theta_{4} \\
\theta_{5}\end{array}$ & $\begin{array}{r}-.00425 \\
.00523 \\
-.03555 \\
.31595 \\
-.14303\end{array}$ & $\begin{array}{l}.00170 \\
.00103 \\
.00458 \\
.07564 \\
.00376\end{array}$ \\
\hline $\begin{array}{l}\sigma_{11} \\
\sigma_{21} \\
\sigma_{22} \\
\sigma_{31} \\
\sigma_{32} \\
\sigma_{33} \\
\sigma_{41} \\
\sigma_{42} \\
\sigma_{43} \\
\sigma_{44} \\
\sigma_{51} \\
\sigma_{52} \\
\sigma_{53} \\
\sigma_{54} \\
\sigma_{55}\end{array}$ & $\begin{array}{r}.08453 \\
-.00326 \\
.05613 \\
.00073 \\
-.00255 \\
.04297 \\
-.00354 \\
.00001 \\
-.00194 \\
.00926 \\
.00008 \\
.00253 \\
-.00011 \\
-.00157 \\
.00516\end{array}$ & $\begin{array}{l}.00483 \\
.00129 \\
.00125 \\
.00135 \\
.00045 \\
.00108 \\
.00025 \\
.00006 \\
.00041 \\
.00019 \\
.00012 \\
.00024 \\
.00022 \\
.00019 \\
.00011\end{array}$ \\
\hline $\begin{array}{r}\delta_{0} \\
\delta_{1} \\
\gamma\end{array}$ & $\begin{array}{r}-.23047 \\
.15072 \\
-.07126\end{array}$ & $\begin{array}{l}.07574 \\
.00861 \\
.00341\end{array}$ \\
\hline $\begin{array}{c}\eta_{1} \\
\eta_{2} \\
\eta_{3} \\
\eta_{4}\end{array}$ & $\begin{array}{l}.00122 \\
.00090 \\
.00064 \\
.00060\end{array}$ & $\begin{array}{l}.00025 \\
.00018 \\
.00014 \\
.00011\end{array}$ \\
\hline
\end{tabular}


Table 3

Correlation Matrix for the State Variables. This table reports the instantaneous correlation matrix for the state variable vector implied by the maximum likelihood estimates of the parameters in Table 2.

\begin{tabular}{|c|c|c|c|c|c|}
\hline & $X_{1}$ & $X_{2}$ & $X_{3}$ & $X_{4}$ & $X_{5}$ \\
\hline$X_{1}$ & 1.0000 & & & & \\
\hline$X_{2}$ & -.0579 & 1.0000 & & & \\
\hline$X_{3}$ & .0169 & -.0602 & 1.000 & & \\
\hline$X_{4}$ & -.3505 & .0209 & -.1972 & 1.0000 & \\
\hline$X_{5}$ & .0132 & .4226 & -.0440 & -.2422 & 1.0000 \\
\hline
\end{tabular}




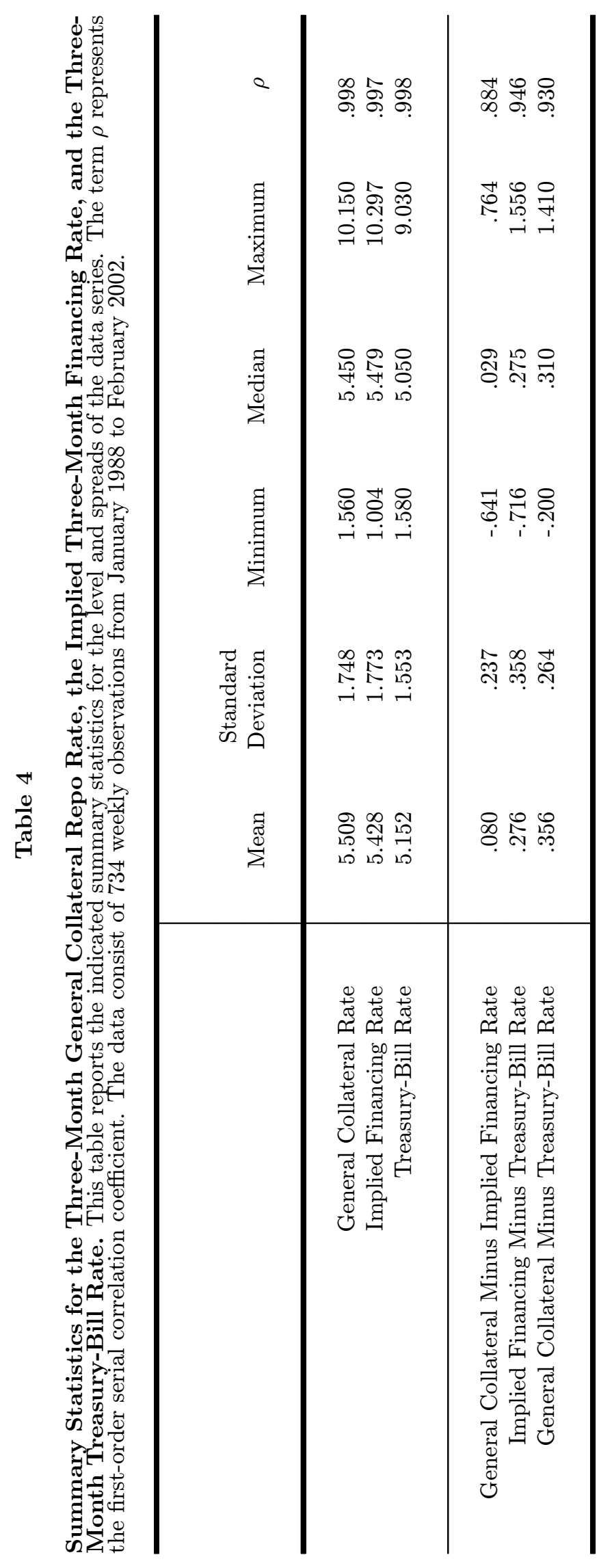




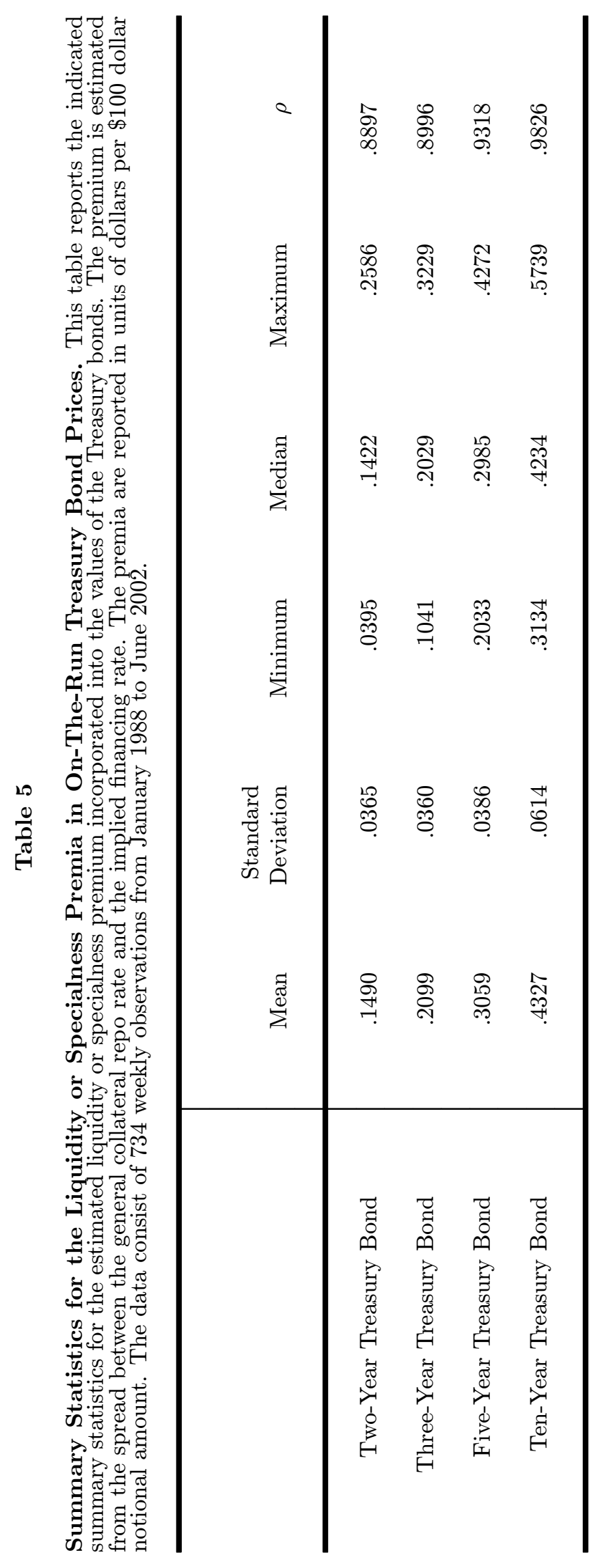




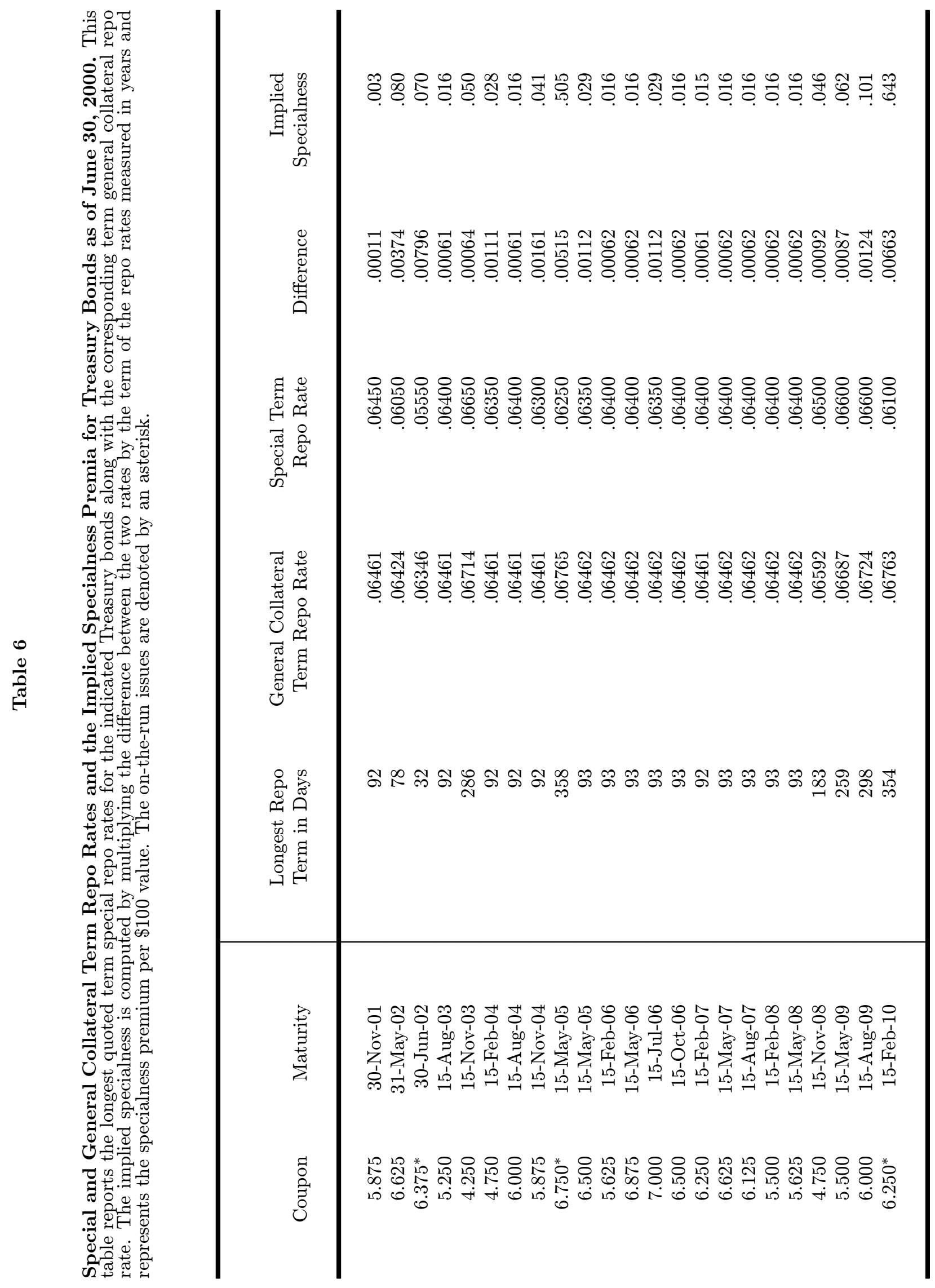




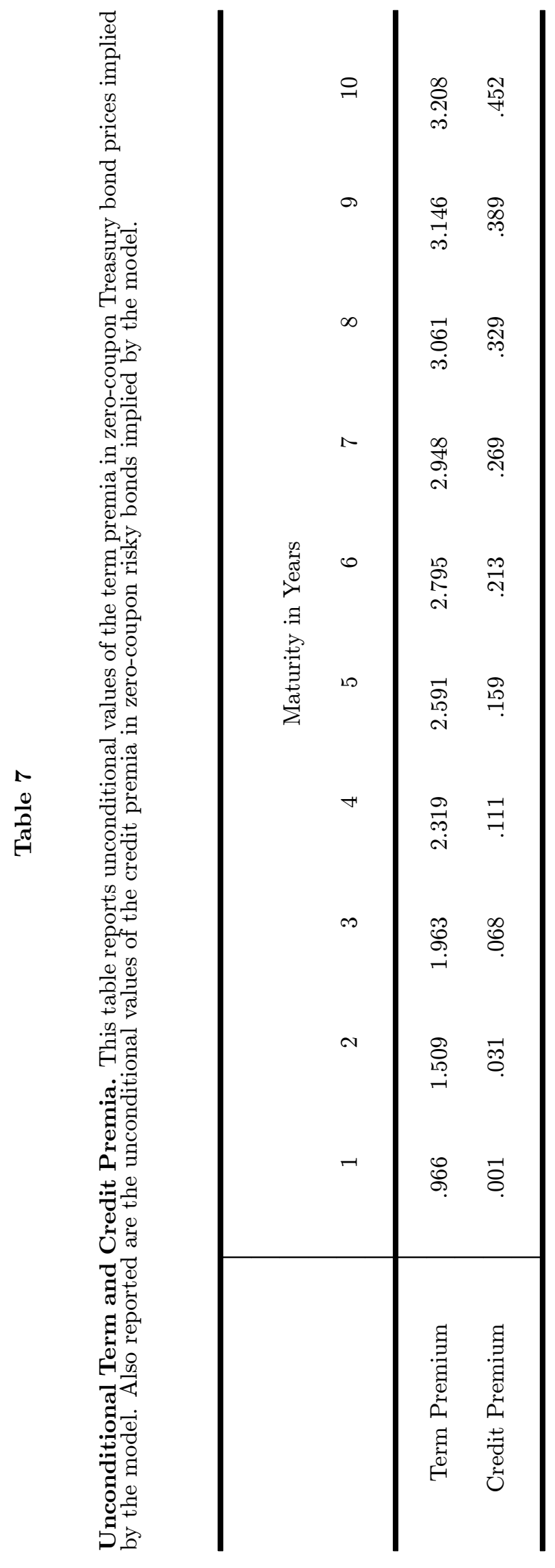



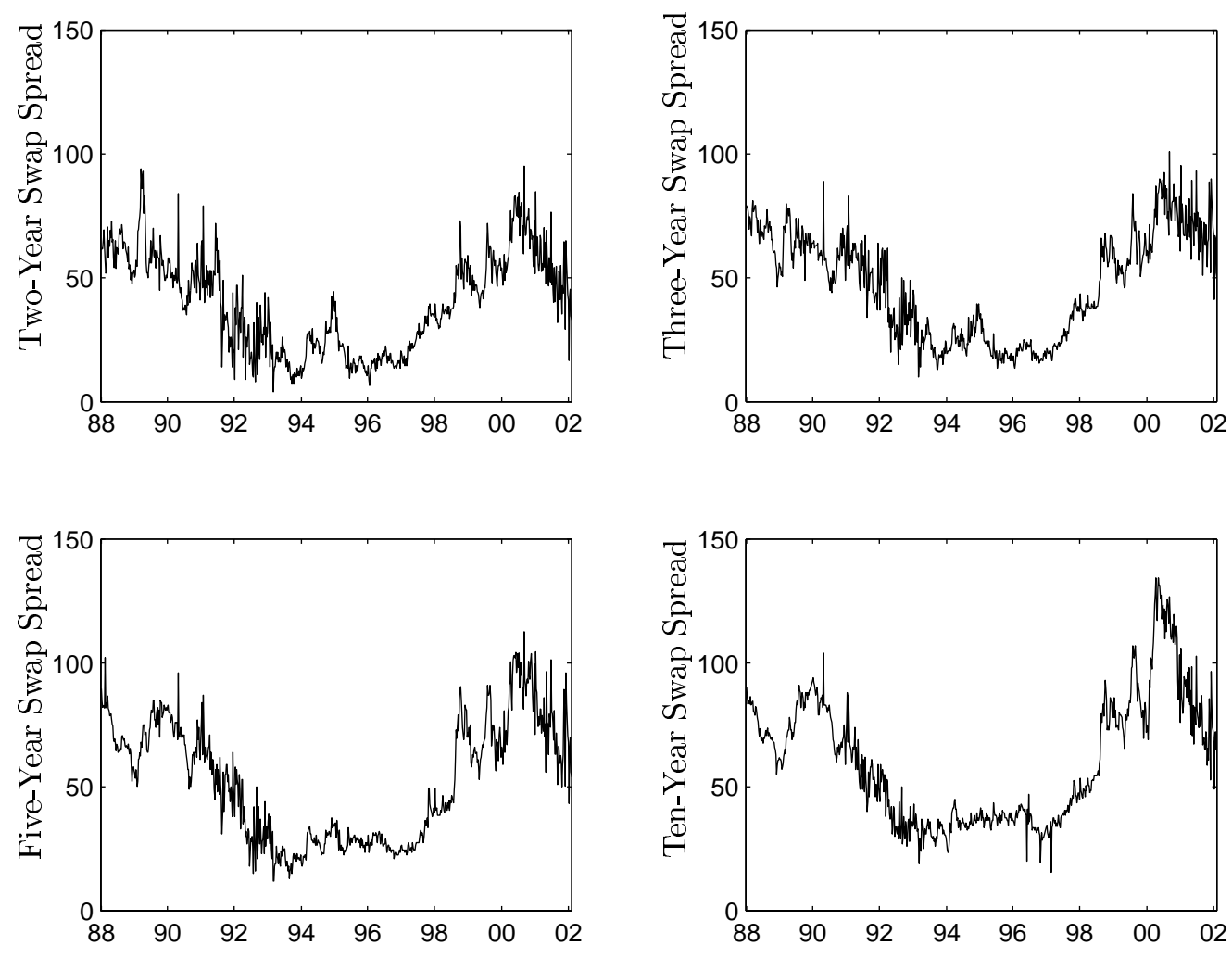

Figure 1. Swap Spreads. Weekly time series of swap spreads measured in basis points. The sample period is from January 1988 to February 2002. 

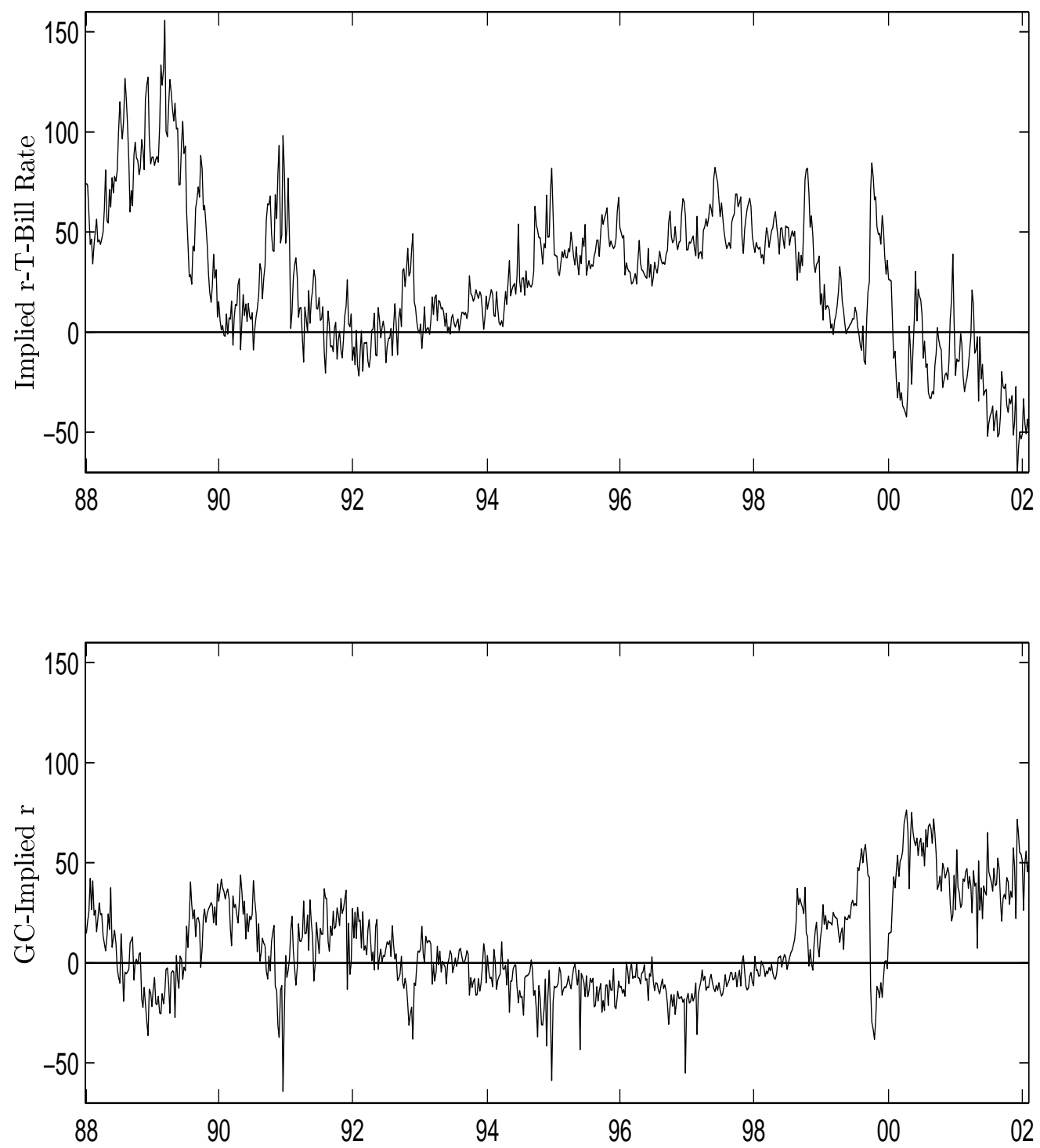

Figure 2. Implied Financing Rate Spreads. Weekly time series of the spread between the implied financing rate $\mathrm{r}$ and the Treasury-bill rate, and of the spread between the general collateral repo rate GC and the implied financing rate. Spreads are measured in basis points. The sample period is from January 1988 to February 2002. 


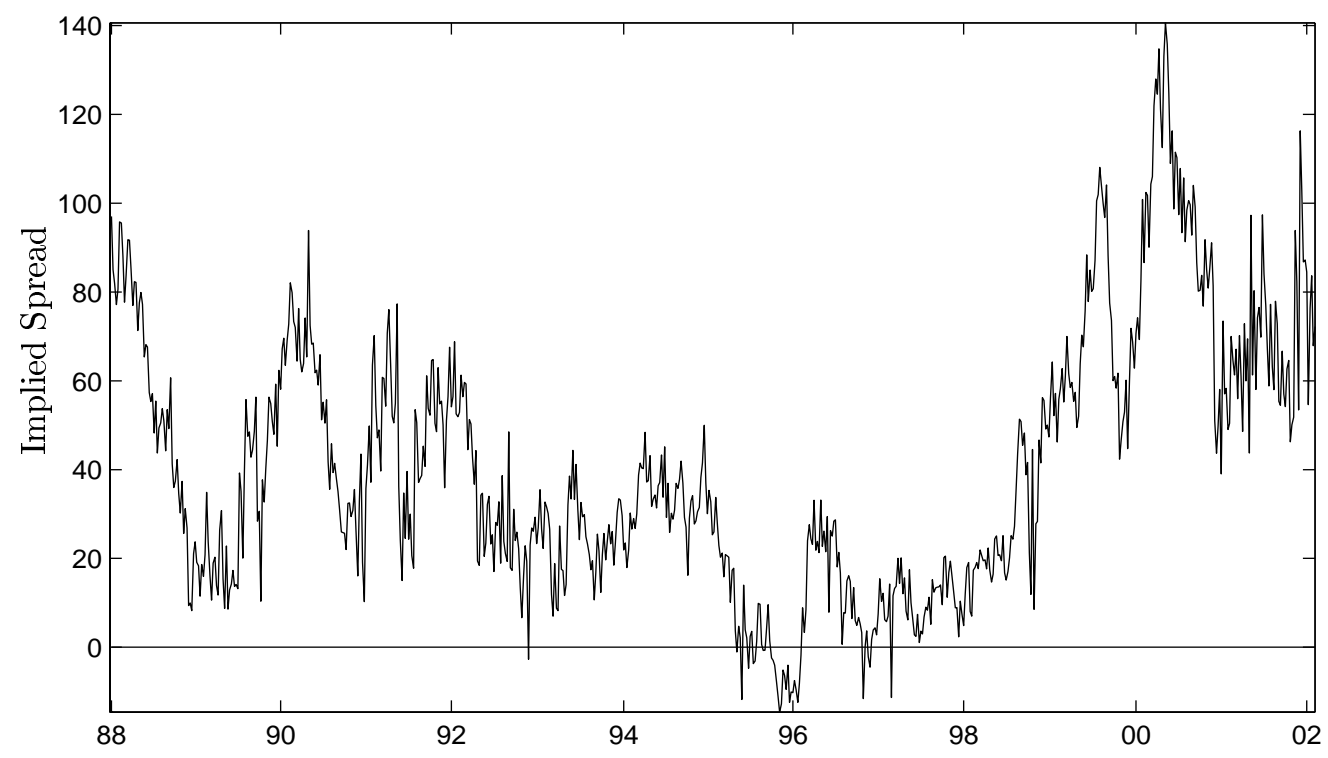

Figure 3. The Implied Credit Spread. The weekly time series of the implied credit spread. The credit spread is measured in basis points. The sample period is from January 1988 to February 2002. 

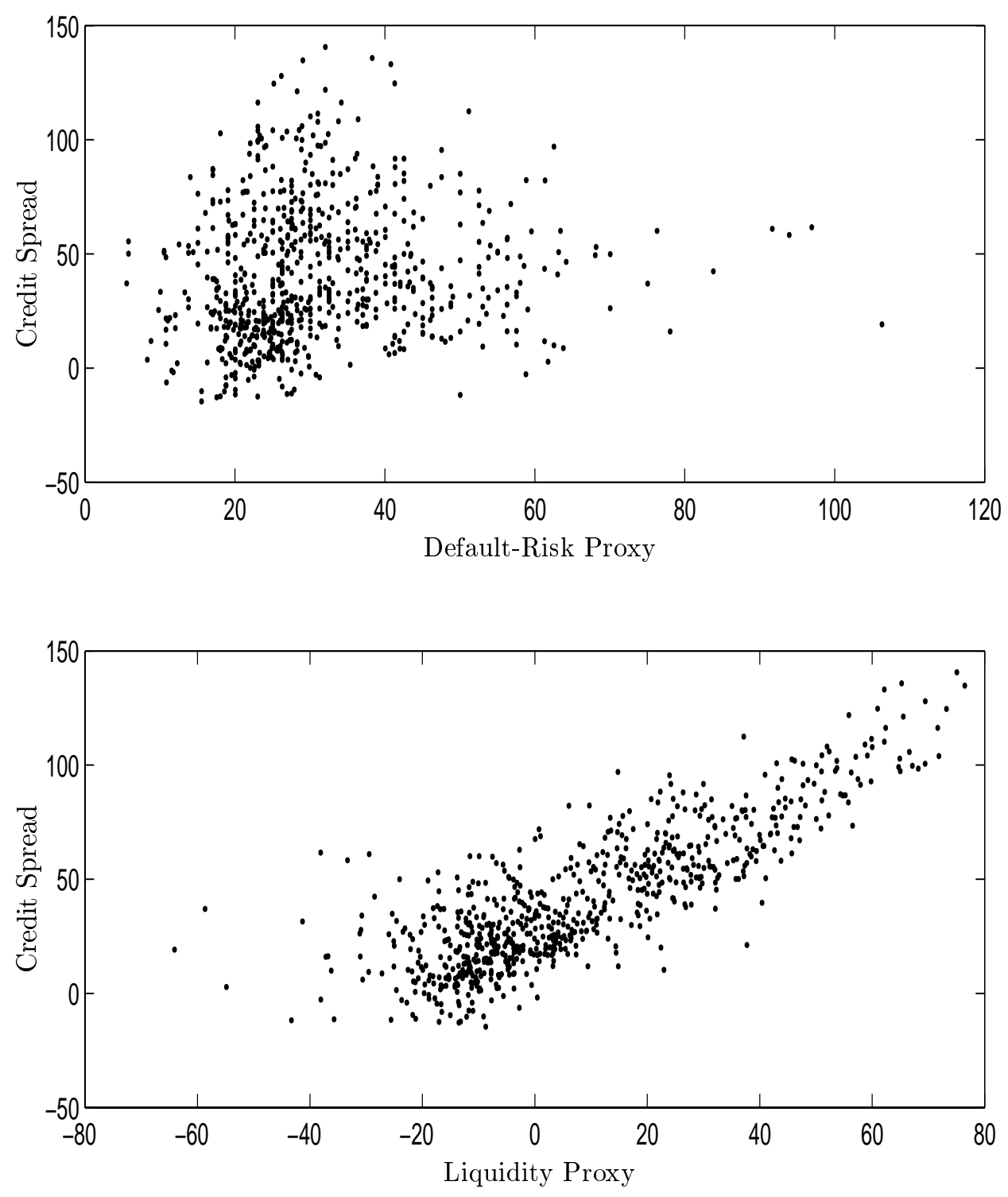

Figure 4. Scatterdiagrams of the Credit Spread against Default Risk and Liquidity Proxies. The top graph plots the implied credit spread against the default-risk proxy. The bottom graph plots the implied credit spread against the liquidity proxy. The credit spread and the default-risk and liquidity proxies are measured in basis points. 

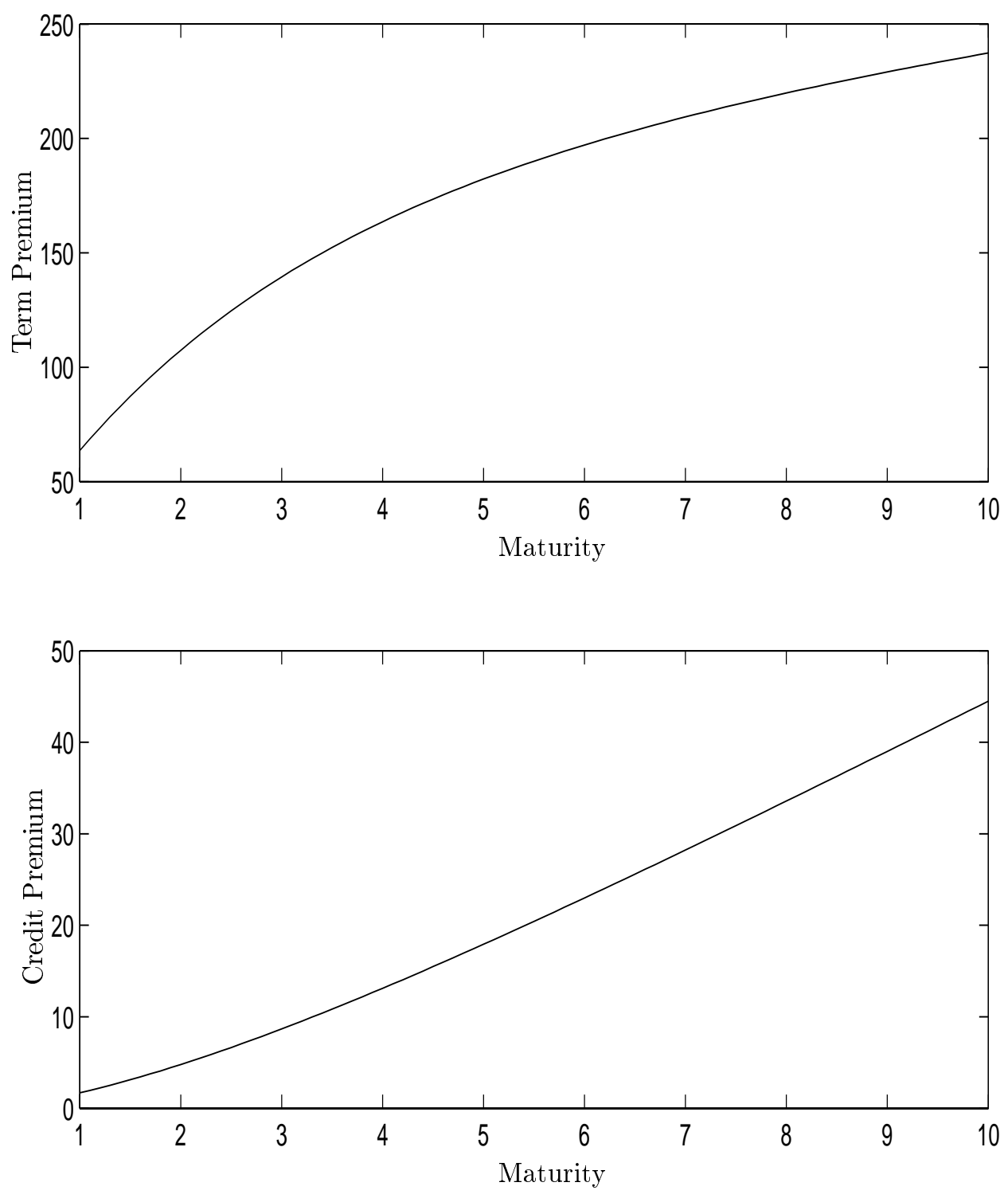

Figure 5. Unconditional Premia. The top graph plots the unconditional term premium of a riskless zero-coupon bond against the maturity of the bond in years. The bottom graph plots the unconditional credit premium of a risky zerocoupon bond against the maturity of the bond in years. Premia are measured in basis points. 

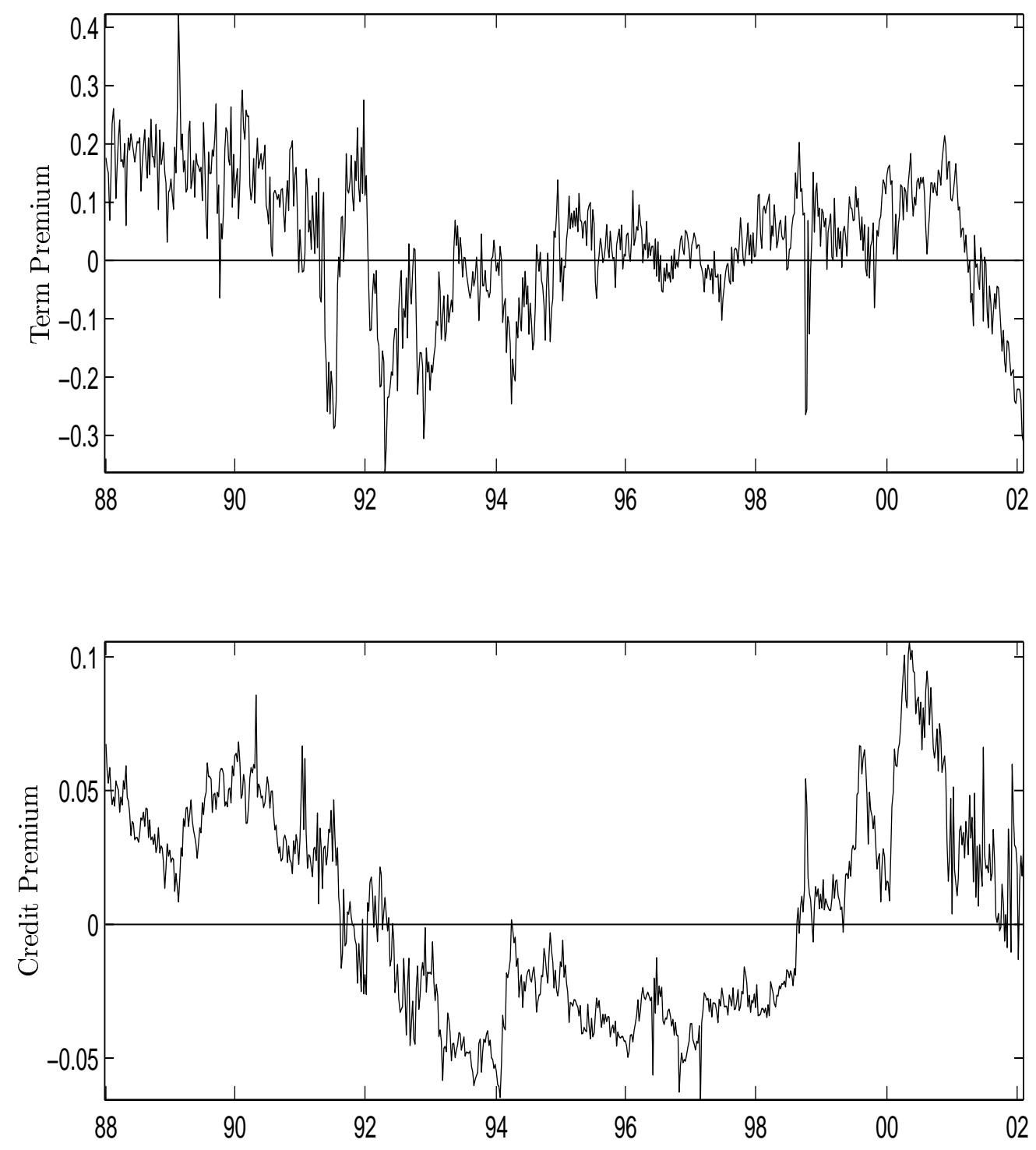

Figure 6. Conditional Premia. The top graph plots the conditional term premium for a riskless ten-year zero-coupon bond. The bottom graph plots the conditional credit premium for a risky ten-year zero-coupon bond. The sample period is from January 1988 to February 2002. 